\section{A orientalização do Ocidente como superfície de emergência de novos paradigmas em saúde}

\section{The orientalization of the West as a surface of emergence for new paradigms in health}

Maria Inês Nogueira

Instituto de Medicina Social (IMS) - Universidade do Estado do Rio de Janeiro (Uerj)

Rua Marquesa de Santos, 5/402 - Laranjeiras

22221-080 Rio de Janeiro - RJ - Brasil minogueira@globo.com

Kenneth Rochel de Camargo Jr. Instituto de Medicina Social (IMS) - Universidade do Estado do Rio de Janeiro (Uerj)

Rua Afonso Pena 141/402

20170-244 Rio de Janeiro - RJ - Brasil

kenneth@uerj.br
NOGUEIRA, Maria Inês; CAMARGO JR., Kenneth Rochel de. A orientalização do Ocidente como superfície de emergência de novos paradigmas em saúde. História, Ciências, Saúde - Manguinhos, Rio de Janeiro, v.14, n.3, p.841-861, jul.-set. 2007.

Este artigo traça as condições de possibilidade - configuradas pelo processo de orientalização do Ocidente - para o surgimento de novos paradigmas em saúde nas sociedades ocidentais. Para tal, esboça uma análise do conceito de superfície de emergência, elaborado por Michel Foucault, e a seguir desenvolve o tema da orientalização do Ocidente tal como foi descrito por Colin Campbell. Associa a ascensão crescente das medicinas alternativas e o florescimento de novas práticas de saúde em nosso meio à alternância histórica de uma teodicéia ocidental para uma outra que é caracteristicamente oriental.

PALAVRAS-CHAVE: medicinas alternativas; paradigma; orientalização; superfície de emergência; teodicéia.

NOGUEIRA, Maria Inês; CAMARGO JR., Kenneth Rochel de. The orientalization of the West as a surface of emergence for new paradigms in health. História, Ciências, SaúdeManguinhos, Rio de Janeiro, v.14, n.3, p.841-861, July-Sept. 2007.

In this article we seek to describe the conditionsconfigured by the process of orientalization of the West - for the emergence of new health paradigms in western society. We set out an analysis of the concept of surfaces of emergence, as put forth by Michel Foucault, followed by an investigation of orientalization in the West as described by Colin Campbell. We use this to associate the growing rise of alternative medicines and the blossoming of new health practices in our midst with the historical alternation from one western theodicy to another that is characteristically oriental.

KEYWORDS: alternative medicine; paradigm; orientalization; surfaces of emergence; theodicy. 
$\mathrm{E}$ ste artigo surgiu de uma indagação suscitada no decorrer da realização da tese de doutorado Entre a conversão e o ecletismo: de como médicos brasileiros tornam-se 'chineses' (Nogueira, 2003), qual seja: que motivos levariam médicos de formação ocidental a optarem pelo estudo da medicina tradicional chinesa, sistema médico originário de uma cultura tão diferente e remota e baseado em premissas também completamente diferentes? Nas entrevistas realizadas constatamos que uma parcela significativa desses médicos relatava um passado de interesse por sistemas de pensamento e práticas terapêuticas orientais, durante a formação acadêmica ou mesmo antes, em consonância com o ethos da geração influenciada pelo movimento da contracultura.

Ao mesmo tempo, o crescente aumento da demanda pelas medicinas ditas alternativas tem sido considerável em nossa sociedade, principalmente a partir das últimas duas décadas do século passado. Assim, esse cenário de abertura da sociedade ocidental contemporânea para as práticas de saúde e sistemas de cura orientais nos levou a perguntar pelas origens desse processo, ou melhor, a indagar sobre as condições de possibilidade para a irrupção de diferentes paradigmas em saúde em nosso meio.

Nesta reflexão tratamos de um Oriente que não é o da geografia, mas de uma região mais imaginária que real, vagamente associada à extensa área que vai do Oriente Médio ao Japão, agrupada num 'outro lugar' mitológico pelo referencial eurocêntrico. Afinal, no processo cultural global contemporâneo, conforme o registro de Appadurai (1996), a imaginação desempenha um novo papel na vida social, tornando-se um campo organizado de práticas sociais. Por essa ótica, a imaginação não é meramente uma fantasia, um simples escape, um passatempo elitista ou uma contemplação. A imaginação é agora uma categoria central para todas as formas de agência, tornando-se ela mesma um fato social e um componentechave da nova ordem global. Vivemos em 'mundos imaginados', verdadeiros blocos de construção, nos quais as linhas entre paisagens realistas e ficcionais são indistintas, quase obscuras. Imagens de fluxo, incerteza, volatilidade e caos estão substituindo velhas imagens de ordem, estabilidade e sistematicidade. É, portanto, nesse contexto sociocultural que se localiza esta reflexão.

Apesar do fascínio que o Oriente exerce sobre o Ocidente, podemos observar que tal atração é marcada por uma antiga ambi-valência. O Oriente é visto, por um lado, como uma civilização de rica tradição cultural, símbolo de sublimidade espiritual, força inspiradora e fonte de sabedoria; por outro, como uma região sombria de impenetrável mistério, irracional, não-científica, portadora de um exotismo sinistro e ameaçador. De fato, o Oriente é um lugar que nos convida a vôos imaginativos e exageros de toda espécie. Esse olhar ambivalente do Ocidente para o Oriente se expressa na grande 
1 'Orientalismo' tornou-se um termo bastante problemático, difícil de ser utilizado em sentido neutro. Surgiu inicialmente na França (1830) e tem sido empregado desde então de várias maneiras. Edward Said (1990) refere-se ao orientalismo como um "enquadramento ideológico do Oriente pelo imperialismo ocidental" (Clarke, 1997, p.7). Nesse caso, há uma preocupação de Said principalmente com o mundo islâmico do Oriente Médio. Clarke (1997) emprega a palavra orientalismo para se referir à gama de atitudes que tem sido manifestada no Ocidente em relação às idéias e aos sistemas filosóficos e religiosos tradicionais do sul e do leste asiático. A abordagem de Clarke não enfoca o orientalismo como uma construção puramente ocidental nem como um objeto cultural unificado, mas, ao contrário, como um contramovimento que, muitas vezes, tende mais a subverter do que a confirmar a estrutura discursiva do poder imperial. variedade de estereótipos e mitos sobre as civilizações orientais que povoam o imaginário ocidental. Desse modo, o Oriente tanto é percebido como exuberante, colorido, sensual e tentador, como pode ser designado por expressões carregadas de um significado de crueldade e obscurantismo, como 'perigo amarelo' ou 'hostes asiáticas'. Sem falar do tão decantado misticismo religioso e do êxtase espiritual procurado por muitos ocidentais (Clarke, 1997, p.3-4).

Numa leitura psicológica, o Oriente é o repositório de toda a escuridão e o mistério - o inconsciente -, multiplicando-se as associações com o feminino, o sensual e o reprimido. O Oriente é 'o outro' e, como uma metáfora especular, poderá refletir todas as nossas próprias inadequações.

A respeito de um possível encontro entre Oriente e Ocidente, Clarke (1997) explora, em seu livro Oriental enlightenment: the encounter between Asian and Western thought, o papel do orientalismo ${ }^{1}$ na moderna tradição intelectual do Ocidente, demonstrando em detalhes de que modo as idéias do Oriente têm se infiltrado em vários campos, como o da filosofia, da religião e da psicologia ocidentais. No entanto, apesar do crescente impacto sobre o Ocidente de tradições originárias de países asiáticos como o hinduísmo, o budismo, o confucionismo e o taoísmo, permanecem enraizadas atitudes eurocêntricas que marginalizam tais contribuições da vida cultural, espiritual e intelectual do Ocidente. Com freqüência deparamos com a visão de um Oriente econômica e tecnologicamente atrasado, perdido em um passado estagnante, até que seja abruptamente despertado pelo impacto modernizante ocidental. Dicotomias são automaticamente estabelecidas, com os atributos de heróico/dinâmico/ libertário para o Ocidente, em contraponto com estagnante/passivo/despótico para o Oriente.

Não é recente o debate sobre as possibilidades e os benefícios advindos do encontro entre essas duas tradições. Clarke (1997) retoma mais uma vez a discussão e, utilizando-se de um ponto de vista poético, apresenta as opiniões contraditórias de escritores como Goethe e Kipling:

He who knows himself and other,

Will also recognise that East and

West cannot be separated.

(Goethe)

Oh, East is East, and West is West,

And never the twain shall meet.

Till Earth and Sky stand presently,

At God's great Judgement Seat.

(Kipling) 
Abstendo-nos de compartilhar de qualquer uma das posições mencionadas, entretanto concordamos que tanto Oriente como Ocidente vivenciam respectivamente processos de ocidentalização e orientalização, principalmente ao longo do século passado.

Nesta discussão, nos deteremos especialmente sobre o processo de orientalização do Ocidente, considerado como superfície de emergência de novos paradigmas em saúde. Para tal, esboçamos uma análise do conceito de superfície de emergência elaborado por Michel Foucault (1987) e, a seguir desenvolvemos o tema da orientalização do Ocidente como foi descrito por Colin Campbell (1997).

\section{O conceito de superfície de emergência em Foucault}

Em sua Arqueologia do saber, Foucault (1987) faz um alerta inicial sobre a questão da análise histórica estrutural, "que parece apagar, em benefício das estruturas fixas, a irrupção dos acontecimentos" (p.6), e sugere que, em vez de empreender análises totalizantes, prestemos "uma atenção cada vez maior aos jogos da diferença" (p.7). Propõe o desenho de uma história nova, ou melhor, uma leitura histórica nova das idéias e do saber, enfatizando, assim, o contraponto entre a história pura e simples e "a história do pensamento, dos conhecimentos, da filosofia, da literatura, [que parecem] multiplicar as rupturas e buscar todas as perturbações da continuidade" (p.6). Note-se, como assinalam Machado (1981) e Gutting (1989), a relação do pensamento de Foucault nesse ponto particular - ênfase em rupturas - com Bachelard e Canguilhem (este último seu professor).

Foucault coloca em dúvida as possibilidades de totalização na história das idéias, do pensamento e das ciências e apresenta uma crítica da história tradicional:

Esta [a história], na verdade, sob sua forma tradicional, se atribuía como tarefa definir relações (de causalidade simples, de determinação circular, de antagonismo, de expressão) entre fatos ou acontecimentos datados ... daí a necessidade de distinguir não mais apenas acontecimentos importantes (com uma longa cadeia de conseqüências) e acontecimentos mínimos, mas sim tipos de acontecimentos de nível inteiramente diferente (alguns breves, outros de duração média, como a expansão de uma técnica ... outros de ritmo lento) ... daí a possibilidade de fazer aparecerem séries com limites amplos, constituídas de acontecimentos raros ou de acontecimentos repetitivos. (Foucault, 1987, p.8-9)

Entretanto, em sua empreitada, Foucault (1987) constata que há um trabalho negativo a ser feito: "libertar-se de todo um jogo de noções que diversificam, cada uma à sua maneira, o tema da continuidade" (p.23). E pede que se abandonem as noções de tradição, influência, desenvolvimento, evolução e mentalidade ou espírito: 
É preciso pôr em questão, novamente, essas sínteses acabadas, esses agrupamentos que, na maioria das vezes, são aceitos antes de qualquer exame, esses laços cuja validade é reconhecida desde o início ... E ao invés de deixá-las ter valor espontaneamente, aceitar tratar apenas ... de uma população de acontecimentos dispersos. (Foucault, 1987, p.24)

Na verdade, Foucault recusa as categorias tradicionais de análise, em razão de importarem pressupostos teóricos não percebidos e não desejados.

Portanto, segundo o autor, todas as formas prévias de continuidade, todas as sínteses que não se problematizam devem ser mantidas em suspenso:

Não se trata, é claro, de recusá-las definitivamente, mas sacudir a quietude com a qual as aceitamos; mostrar que elas não se justificam por si mesmas, que são sempre o efeito de uma construção cujas regras devem ser conhecidas e cujas justificativas devem ser controladas; definir em que condições e em vista de que análises algumas são legítimas; indicar as que, de qualquer forma, não podem mais ser admitidas. (Foucault, 1987, p.29)

Foucault (1987) propõe que as noções de influência ou evolução, de obra ou livro, ou ainda unidades como a ciência ou a literatura sejam arrancadas de sua quase-evidência, liberando-nos dos problemas que colocam; reconhecendo "que não são o lugar tranqüilo de onde outras questões podem ser levantadas ... mas que trazem em si mesmas todo um feixe de questões" (p.29). Ou seja: é necessário reconhecer que essas noções talvez não sejam o que se acreditava serem à primeira vista. “Enfim, que exigem uma teoria [a qual, para ser elaborada, deverá fazer surgir] o campo dos fatos do discurso a partir do qual são construídas" (p.29).

Antes de tudo, para melhor conduzir esta discussão, utilizamos Machado (1981) para fazer a distinção entre a epistemologia e a arqueologia foucaultiana. A epistemologia, ao menos como é usualmente definida na literatura francesa, é uma reflexão sobre a produção de conhecimentos científicos que tem por objetivo avaliar a ciência do ponto de vista de sua exatidão ou veracidade - em última análise, o que daria à ciência sua especificidade. Na tradição inaugurada por Bachelard e que teve em Canguilhem seu continuador, a epistemologia, para dar conta das condições de possibilidade dos conhecimentos científicos, elege a história como instrumento privilegiado de análise, relacionando a reflexão filosófica com uma análise histórica das ciências. Para a epistemologia, a ciência é o lugar próprio do conhecimento e da verdade e, como tal, é instauradora de racionalidade. "E, se a razão tem uma história, só a história das ciências é capaz de demonstrá-lo e indicar o seu itine- 
rário ... A epistemologia é, portanto, uma filosofia que tematiza a questão da racionalidade através da ciência, por ela considerada como atividade racionalista por excelência" (p.9-10).

A arqueologia foucaultiana, de acordo com Machado (1981), é fruto de um importante deslocamento metodológico perante a epistemologia, operado com a finalidade de dar conta de sua especificidade como história dos discursos. Situando-se numa posição de independência com relação a qualquer ciência, critica a própria idéia de racionalidade e elege um novo objeto - o saber. Todas as suas análises estão centradas na questão do homem, formando uma grande pesquisa sobre a constituição histórica das 'ciências do homem' na modernidade:

Abandonando a questão da cientificidade - que define o projeto epistemológico - a arqueologia realiza uma história dos saberes de onde desaparece qualquer traço de uma história do progresso da razão. ... [Portanto, a arqueologia] sempre procurou mostrar como a história epistemológica se encontrava na impossibilidade de analisar convenientemente o tipo de problema de que ela pode dar conta. Parece-nos mesmo que a riqueza do método arqueológico é ser um instrumento capaz de refletir sobre as ciências do homem enquanto saberes - investigando suas condições de existência através da análise do que dizem, como dizem e por que dizem. (Machado, 1981, p.11)

Qual seria então o procedimento a ser utilizado na análise arqueológica? Certamente nada rigidamente definido, como tão bem esclarece Roberto Machado em Ciência e saber: a trajetória da arqueologia de Michel Foucault (Machado, 1981). A própria idéia de um método acabado é desprestigiada na arqueologia de Foucault. No entanto, a passagem da epistemologia para a arqueologia não se deu imediatamente da ciência para o saber. Eis o motivo pelo qual se fala de uma 'trajetória da arqueologia'. Como esclarece o autor,

É a originalidade da psiquiatria e da medicina que exige a especificidade de um método capaz de esclarecer e reconstituir sua história; é a diferença dessas disciplinas, com relação aos conhecimentos científicos propriamente ditos como a física ou a química, que impede que elas sejam estudadas de forma eficaz em uma perspectiva epistemológica. (Machado, 1981, p.12)

Desse modo, a história arqueológica se coloca em uma região distinta com relação às regiões estudadas pelos epistemólogos, definindo-se como uma 'arqueologia da percepção' (na análise da psiquiatria) ou uma 'arqueologia do olhar' (na análise da medicina). E ampliando o âmbito da análise, saindo dos limites de uma região, formula em um nível anterior ao da história epistemológica seu novo objeto - o deslocamento de uma região para um nível 
que assinala o nascimento de uma 'arqueologia do saber' (Machado, 1981, p.12).

Histoire de la folie à l'Âge Classique, lançado em 1972, marca o início da série de análises históricas arqueológicas empreendidas por Foucault. Seu objetivo consiste em estabelecer as condições históricas de possibilidade dos discursos e das práticas que dizem respeito ao louco considerado como doente mental. Nesse livro o autor faz uma história da 'percepção' e do 'conhecimento', e não uma história da 'experiência' da loucura, conforme assinala Machado (1981, p.94). A História da loucura é, portanto, uma arqueologia da percepção, já que analisa "a relação teórica e prática estabelecida com o louco em uma situação de exclusão institucional" (p.81).

Nesse trabalho, Foucault foi capaz de explicitar as condições de possibilidade históricas da psiquiatria através da análise dos saberes teóricos e, principalmente, das práticas de internamento e das instâncias sociais (família, Igreja, justiça, medicina) a elas relacionadas, juntamente com a análise das causas econômicas e sociais das modificações institucionais. Sobre a importância da obra, Machado comenta:

Demonstra, por um lado, que a psiquiatria é uma 'ciência' recente: que a doença mental não tem nem mesmo duzentos anos, como também que a intervenção da medicina com relação ao louco, em vez de ser atemporal, é historicamente datada. ... [Enfim, depois de Histoire de la folie] não é mais possível falar rigorosamente de doença mental antes do final do século XVIII, momento em que se inicia o processo de patologização do louco. (Machado, 1981, p.58)

Para ilustrar a estratégia utilizada por Foucault, vejamos como ele analisa uma unidade inteiramente formada, como a psicopatologia. Inicialmente o trabalho é de demarcação das 'superfícies primeiras de sua emergência'. Foucault chama de 'superfície de emergência' o conjunto de condições de possibilidade - institucionais, cognitivas, históricas - que demarcam o surgimento de novas práticas discursivas. Essas superfícies de emergência não são as mesmas nas diferentes sociedades, em diferentes épocas e nas diferentes formas de discurso.

Quanto às superfícies de emergência da psicopatologia do século XIX, Foucault sugere que elas foram constituídas pela família, pelo grupo social próximo, pelo meio de trabalho, pela comunidade religiosa. Todas essas instâncias são normativas, suscetíveis ao desvio, possuem uma margem de tolerância e um limiar a partir dos quais a exclusão é requerida, têm um modo de designação e de rejeição da loucura e transferem para a medicina a carga explicativa da cura e do tratamento. Foi também no século XIX que se puseram a funcionar novas 'superfícies de aparecimento': a arte com sua 
normatividade própria, a sexualidade (seus desvios em relação a proibições habituais tornam-se pela primeira vez objeto de demarcação, descrição e análise para o discurso psiquiátrico) e a penalidade (a criminalidade torna-se uma forma de desvio aparentada à loucura, como por exemplo as 'monomanias homicidas'). Assim, nesses campos de diferenciação primeira "o discurso psiquiátrico encontra a possibilidade de limitar seu domínio, de definir aquilo de que se fala, de dar-lhe o status de objeto - ou seja, de fazê-lo aparecer, de torná-lo nomeável e descritível" (Foucault, 1987, p.47).

Num segundo momento, o autor aponta as 'instâncias de delimitação': a medicina (instância superior que distingue, designa, nomeia e instaura a loucura como objeto), juntamente com a justiça (particularmente a justiça penal), a autoridade religiosa e as críticas literária e artística. E, finalmente, analisa as 'grades de especificação', sistemas segundo os quais se processam a separação, oposição, associação e classificação das diferentes 'loucuras' como objetos do discurso psiquiátrico. No século XIX essas grades de especificação foram a alma, o corpo, a vida e a história dos indivíduos e os jogos das correlações neuropsicológicas (Foucault, 1987, p.48).

Em termos gerais, Foucault afirma que o discurso psiquiátrico, no século XIX, caracteriza-se não por objetos privilegiados, mas pela maneira com que forma seus objetos. Essa formação é assegurada por um conjunto de relações estabelecidas entre as instâncias de emergência, de delimitação e de especificação. Observemos ainda um comentário de Foucault a esse respeito:

Se, em nossa sociedade, em uma época determinada, o delinqüente foi psicologizado e patologizado, se a conduta transgressora pôde dar lugar a toda uma série de objetos de saber, deve-se ao fato de que, no discurso psiquiátrico, foi empregado um conjunto de relações determinadas. ... São essas relações que, atuando no discurso psiquiátrico, permitiram a formação de todo um conjunto de objetos diversos. (Foucault, 1987, p.49-50)

Foucault, ao falar sobre as condições de possibilidade para que apareça um objeto de discurso, isto é, as condições históricas necessárias ao surgimento desse objeto, adverte-nos que não se pode falar de qualquer coisa em qualquer época e que não é fácil dizer alguma coisa nova:

não basta abrir os olhos, prestar atenção, ou tomar consciência, para que novos objetos logo se iluminem e na superfície do solo, lancem sua primeira claridade ... ele [o objeto] não preexiste a si mesmo, retido por algum obstáculo aos primeiros contornos da luz, mas existe sob as condições positivas de um feixe completo de relações. (Foucault, 1987, p.51) 
Assim, de acordo com Foucault, nas análises arqueológicas tratase sempre de análises de discurso. Não se faz distinção entre tipos de discursos e não se obedece às tradicionais distribuições dos discursos em ciência, poesia, romance, filosofia etc., o que permite dar conta do que se diz em todos esses domínios sem se limitar por tais divisões. Note-se, portanto, que ao mesmo tempo que Foucault enfatiza as descontinuidades históricas, também assinala contigüidades discursivas entre várias regiões do saber, inclusive entre o que é considerado ciência e o que não o é.

Quanto às 'relações discursivas', Foucault esclarece que as mesmas não são internas nem exteriores ao discurso, mas estão, de alguma maneira, no limite dele. Ou seja: "Essas relações caracterizam não a língua que o discurso utiliza, não as circunstâncias em que ele se desenvolve, mas sim o próprio discurso enquanto prática" (Foucault, 1987, p.52-53).

Em resumo, a proposta analítica foucaultiana consiste em fazer uma história dos objetos discursivos. Para Foucault, os 'discursos' não são um puro e simples entrecruzamento de coisas e palavras, tampouco uma estreita superfície de contato, ou de confronto, entre uma realidade e uma língua, ou o enredamento de um léxico com uma experiência:

analisando os próprios discursos, vemos se desfazerem os laços aparentemente tão fortes entre as palavras e as coisas, e destacarse um conjunto de regras próprias da prática discursiva ... [Portanto, não se deve] tratar os discursos como conjunto de signos (elementos significantes que remetem a conteúdos ou a representações), mas como práticas que formam sistematicamente os objetos de que falam. (Foucault, 1987, p.56)

Por conseguinte, a transformação trazida pela análise histórica arqueológica consiste em tratar os documentos como monumentos, ou mais precisamente, tratar o discurso não como 'documento', mas como 'monumento'. Neste sentido, a arqueologia, ao analisar as regras de formação de um determinado discurso, procura determinar as condições de existência desse discurso.

Do mesmo modo, apropriando-nos do olhar arqueológico foucaultiano, consideramos a contracultura como um acontecimento discursivo e o conjunto de discursos produzidos pelo orientalismo, além do próprio discurso sobre a orientalização do Ocidente, como superfície de emergência de novos paradigmas em saúde.

\section{Campbell e a orientalização do Ocidente}

De acordo com o artigo de Colin Campbell, "A orientalização do Ocidente: reflexões sobre uma nova teodicéia para um novo milênio" (Campbell, 1997), ocorre atualmente no Ocidente um 'processo 
2 A palavra teodicéia parece ter sido cunhada por Leibniz, em 1690, para se referir à defesa de Deus contra os ataques efetuados por uma consideração do mal tanto moral como natural. Rapidamente passou a ser usada num sentido mais amplo, para designar o estudo da compatibilidade da idéia de Deus com a existência do mal, e, de maneira ainda mais genérica, como sinônimo da teologia filosófica (Campbell, 2001). de orientalização' caracterizado pelo deslocamento da teodicéia tradicional por uma outra que é essencialmente oriental na sua natureza. Ou seja, o paradigma cultural ou teodicéia que tem sustentado a prática e o pensamento ocidentais por cerca de dois mil anos estaria sofrendo um processo de substituição pelo paradigma que tradicionalmente caracterizou o Oriente.

Com o termo 'orientalização' Campbell não pretende unicamente se referir à introdução e à difusão no Ocidente de produtos reconhecidamente orientais, quer sejam mercadorias materiais tais como temperos, iogurtes, sedas etc.; práticas, como a ioga ou a acupuntura; ou mesmo um sistema religioso completo como o hinduísmo ou o budismo. Como diz o autor: "tanto artefatos materiais quanto idéias podem simplesmente ser absorvidos ou assimilados sem mudar os valores e atitudes predominantes" (Campbell, 1997, p.6). Ele referese, portanto, à orientalização como um processo mais amplo e radical, que consiste na mudança de um paradigma. A despeito de estar sendo ajudado pela introdução de idéias e influências do Oriente no Ocidente, o que tem sido mais importante para apressar essa mudança "são os desenvolvimentos culturais e intelectuais dentro da própria civilização ocidental” (p.6).

No intuito de explicar com clareza o teor dessa mudança, Campbell recorre ao sociólogo Max Weber, que construiu um esquema para classificação e análise das religiões mundiais visando uma melhor compreensão da complexa relação existente entre a estrutura institucional socioeconômica da sociedade e sua cultura. Esse esquema relacionava-se com um conjunto limitado de respostas possíveis que Weber atribuía ao problema da teodicéia ${ }^{2}$ - a explicação dos caminhos de Deus para o homem e, especialmente, a solução do problema do mal. As respostas formuladas envolviam conjecturas sobre a relação entre o divino e o mundo, que podiam se apresentar apenas de dois modos: ou o divino era concebido como imanente (presente em todas as coisas, interpenetrando o mundo cotidiano), ou transcendente (representado como superior e separado do mundo cotidiano, controlando-o de cima).

Essas duas pressuposições contrastantes, foram vistas por Weber como exemplificadas no princípio Brahman-Atman da filosofia religiosa indiana, por um lado, e no Deus criador semita, por outro; duas teodicéias contrastantes que caracterizam as sociedades do Oriente e do Ocidente ... [Após um processo de desenvolvimento cultural, ou racionalização, as duas teodicéias culminaram em dois] sistemas logicamente fechados, representados pela lei do carma, por um lado, e, por outro, pela predestinação calvinista. (Campbell, 1997, p.7)

Conforme nos relata Campbell, Weber conduziu sua análise até a reforma protestante, assumindo que a religião em geral declinaria 
3 Denomina-se secularização ao fenômeno histórico dos últimos séculos pelo qual as crenças e instituições religiosas se converteram em doutrinas filosóficas e instituições leigas.

4 Sobre o movimento romântico e as sucessivas transformações sofridas pelo protestantismo, ver Campbell (2001). pelas forças da secularização. ${ }^{3}$ No entanto, continua o autor, ao se estender a interpretação weberiana até a atualidade, pode-se dizer que ao longo dos séculos XVIII, XIX e XX a teodicéia ocidental sofre sucessivos abalos em seu domínio, entre outras razões pela difusão de idéias mais próximas do modelo oriental, incluindo-se aí componentes de uma visão de mundo também ocidental, ainda que não hegemônica, como por exemplo a expressa pelo romantismo, que veremos adiante.

Assim, a teodicéia calvinista não foi atingida apenas, como parecia crer Weber, pelas forças seculares da razão e da ciência, mas também, e em grande medida, por crenças alternativas como o arminianismo, que tenderam a enfatizar o amor mais que a justiça terrível de Deus. De acordo com Campbell (1997, p.7): “Essa revolução na crença preparou o caminho para uma revolução ainda maior, representada pelo Romantismo ${ }^{4}$, que rejeitou ao mesmo tempo as doutrinas literal e histórica do Cristianismo, enquanto reteve uma crença tanto na bondade da humanidade como na espiritualidade que ligava a natureza do homem ao mundo natural".

Portanto, conforme a interpretação oferecida por Campbell (1997, p.7): “Todas essas crenças construíram os alicerces para a substituição da imagem transcendente do divino tradicionalmente ocidental pela imagem imanente oriental, um processo que, embora venha ocorrendo por cerca de duzentos anos, somente agora começa a se tornar de fato amplamente visível". O autor, então, se pergunta sobre a evidência de que uma mudança historicamente significativa estaria ocorrendo nas crenças da população ocidental como um todo, e aponta "duas áreas em que ela pode ser encontrada: uma é em relação à crença em Deus ou no divino; a outra diz respeito à vida após a morte, ou mais corretamente, à relação desta vida com outras formas de existência" (p.10).

Utilizando pesquisas realizadas regularmente pelo Gallup após a Segunda Guerra Mundial, Campbell nos mostra que o percentual da população da Grã-Bretanha que diz acreditar em Deus tem caído constantemente. No entanto, quando a questão relativa à crença em Deus é aberta em duas subquestões, separando-se a crença em 'um deus pessoal' da crença em 'algum tipo de espírito ou força vital', percebe-se que toda a queda na crença em Deus nesse período se referia ao tradicional deus criador e pessoal. Ao contrário, a proporção de pessoas que admitem a crença em 'algum tipo de espírito ou força vital' não decaiu (como deveria, se a secularização fosse a explicação), mas tem aumentado ligeiramente nos últimos anos. Quanto às crenças das pessoas sobre a relação entre esta vida e outra existência, a proporção da população da Grã-Bretanha que declara acreditar em céu e inferno tem declinado consideravelmente. Porém a crença na reencarnação - que não faz parte oficialmente do credo de nenhuma igreja cristã histórica - vem de fato crescendo 
(Campbell, 1997, p.10). Consideradas isoladamente, conclui o autor, essas duas tendências poderiam não indicar uma mudança dramática na base das crenças da população da Grã-Bretanha e de outros países da Europa Ocidental. Mas quando as mesmas são analisadas em conjunto, e diante da evidência de que todos os itens da fé cristã na sua forma tradicional são agora crenças minoritárias, esses dados sugerem que "uma mudança significativa está ocorrendo, uma mudança que poderá significar a derrocada da teodicéia que tem dominado o pensamento ocidental por dois mil anos" (p.10-11).

No entanto, como observa Campbell (1997, p.13), “um processo de orientalização não tem que depender simplesmente da importação de idéias exógenas, mas pode ser entendido como facilitado pela presença de uma tradição cultural nativa ao Ocidente". De fato, existem várias tradições 'nativas' que podem ser identificadas como importantes para a eclosão da alternância histórica de uma teodicéia ocidental para uma teodicéia oriental.

Uma questão importante, que freqüentemente passa despercebida nas análises sobre sistemas religiosos ocidentais, diz respeito à existência, no cristianismo ocidental, de uma corrente de pensamento imanente e mística, embora minoritária. Quem melhor resumiu a natureza dessa tradição foi Ernest Troeltsch, um historiador social e cultural. Como descreve Campbell (1997), a discussão de Ernest Troeltsch, em 1931, sobre a distinção entre a 'religião de igreja' e a 'religião de seita' incorporou-se ao cânone clássico dos escritos sobre sociologia da religião.

Na classificação que estabelece para as religiões, Troeltsch denominou a terceira categoria 'religião espiritual e mística', cujas crenças podem ser identificadas nos seguintes termos: a unidade da base divina, a semente divina e a crença na evolução espiritual. A meta desse tipo de religião seria alguma forma de união com Deus, ou mais propriamente de reunião. Essa forma de espiritualidade é bem mais parecida com o modelo oriental do que com o ocidental: a concepção do divino é claramente impessoal e imanente, assim como a crença na reencarnação (ainda que não explícita) se ajusta facilmente à idéia de evolução espiritual. Além disso, percebe-se que o conceito oriental de auto-aperfeiçoamento substitui a idéia ocidental de salvação. "Há, assim, a crença numa 'escala de espiritualidade' que atribui graus ao avanço da relação da alma com o divino, concepção que é necessariamente imanentista e nega o dualismo" (Campbell, 1997, p.11).

Campbell (1997) cita duas outras correntes facilitadoras do processo de orientalização que confirmam a presença de uma tradição cultural nativa no próprio Ocidente. A primeira delas seria o neopaganismo, um movimento de retorno a um passado pré-cristão, representado na Europa tanto pelas culturas pagãs do Sul (helênica e druídica), quanto pelas culturas bárbaras do Norte (nór- 
dica e céltica), ao passo que, nas Américas, inclui as tribos indígenas nativas e as culturas asteca e maia. Nesse caso, segundo o autor, "a teodicéia que dominou o Ocidente por dois mil anos é rejeitada não a partir de uma 'virada para o Oriente' ... mas sim, ao contrário, por uma 'volta' mais radical às tradições religiosas que o próprio Ocidente derrotou" (p.13). Na prática, todas essas tradições religiosas estão de acordo com um estilo de espiritualidade ao mesmo tempo panteísta e imanentista.

A segunda corrente seria o Movimento Nova Era. Os movimentos religiosos assim denominados podem ser vistos como essencialmente modernos, uma vez que manifestam um individualismo e um otimismo extremos, enfatizando os valores progressistas de autodesenvolvimento e de auto-satisfação, além de buscarem recompensas neste mundo. Portanto, "a atitude essencialmente neomística de uma psicoterapia contemporânea que busca a salvação nas supostas profundezas da própria consciência humana" [pode ser considerada como] uma forma hindu-budista de misticismo", conclui Campbell (1997, p.14).

Finalmente, o autor menciona outro ramo indicativo da orientalização do Ocidente, que atravessa e complementa as outras correntes já mencionadas, a saber, os movimentos ambientais e ecológicos emergentes. A noção geral de entrelaçamento, não apenas do ser humano com a natureza, mas de toda a vida no planeta e a idéia da unidade metafísica da realidade como um todo, além do caráter quase-religioso e místico são orientais na sua natureza.

Para Campbell (1997), “a década de 1960 foi o momento decisivo crucial, o momento histórico em que uma teodicéia foi efetivamente substituída por outra" (p.17). Nesse período ocorreu uma mudança significativa, isto é, um conjunto de crenças 'essencialmente orientais' foi adotado por uma 'minoria significante e influente que compunha a contracultura'. Entretanto, de acordo com o autor, "levou mais de trinta anos para que elementos relevantes do seu credo tivessem adesão entre a população como um todo" (p.16).

Campbell, ao se questionar sobre a veracidade de sua própria tese - a orientalização recente e progressiva do Ocidente-, levanta uma outra questão importante sobre o tema, ou seja, apesar de já existir uma base no Ocidente para a orientalização, ainda assim 'essa tradição nativa Ocidental de caráter orientalista' não ofereceria uma explicação suficiente para a substituição de paradigmas. Discorre, então, sobre o papel paradoxal desempenhado pela ciência nesse processo:

Para avaliar isso, precisamos reconhecer que os séculos XVIII, XIX e XX testemunharam um progresso no qual o surgimento da ciência serviu para minar, primeiro, a fé das pessoas na religião tradicional, apenas, em seguida, para esvair o otimismo relacio- 
nado à ciência e à tecnologia. Essencialmente, é essa seqüência de eventos que explica por que o paradigma oriental tomou a dianteira. Pois a teodicéia oriental tem uma evidente vantagem sobre a ocidental tradicional na medida em que tanto é menos vulnerável ao ataque da ciência (visto que não é baseada em verdades literais, históricas), como é mais compatível com o pensamento moderno em sua aparente abertura e individualismo. Esse individualismo extremo, juntamente com o anti-dualismo e a relativização das pretensões de verdade, torna-a um alvo muito difícil para o ataque dos racionalistas e cientistas. (Campbell, 1997, p.18)

Em um comentário adicional, Campbell (1997) nos diz que essa mudança parece acontecer por todo o mundo ocidental desenvolvido: Europa Ocidental, Escandinávia, América do Norte e, cada vez mais, Europa Oriental. Entretanto, nos alerta para o fato de que a religião tradicional não perdeu todo seu poder e influência: não se deve ignorar o ressurgimento do islamismo, tampouco o retorno às formas tradicionais do cristianismo no Ocidente, principalmente nos países em desenvolvimento. E mais: as ideologias seculares ainda têm um peso importante na sociedade contemporânea devido à hegemonia da ciência. Ainda assim, reforça o autor, podemos esperar um fortalecimento das "linhas de pensamento essencialmente orientais, descobertas no interior do pensamento das tradições judaica e cristã" (p.19).

Por outro lado, Campbell (1997) nos lembra que, apesar do 'processo de ocidentalização' prosseguir rapidamente no Oriente (inicialmente pela exploração colonial e, em seguida, pelo controle industrial, comercial e financeiro), a grande ironia reside no fato de que o próprio Ocidente não mostra mais um entusiasmo por seus próprios valores e crenças: "Isso está ocorrendo porque aquele paradigma dominante ou teodicéia que serviu tão efetivamente ao Ocidente por dois mil anos finalmente perdeu seu controle sobre a maioria da população na Europa Ocidental e na América do Norte” (p.20).

Então, Campbell conclui sua explanação tecendo considerações bastante otimistas sobre a substituição de paradigma, ou mudança de teodicéia:

[Não se sustenta mais no Ocidente] a visão de um mundo dividido em matéria e espírito e governado por um Deus criador, pessoal e todo-poderoso, que tenha colocado suas criaturas acima do resto da criação ... Em seu lugar, [afirma ele] foi posta a visão fundamentalmente oriental da humanidade como parte da entrelaçada teia de vida espiritual e sensitiva. Parece inevitável que tal mudança revolucionária na visão de mundo dominante anuncie, por sua vez, uma nova consciência ética para o novo milênio. (Campbell,1997, p.20) 
Finalizando a exposição da tese de Campbell sobre a orientalização do Ocidente, vale ressaltar algumas ponderações de Otávio Velho em seus "Comentários a um texto de Colin Campbell" (Velho, 1997). Não obstante a concordância e simpatia básicas com a posição assumida por Campbell, Velho aponta a necessidade de uma reflexão cautelosa, levando em conta todas as complexificações que o seu desenvolvimento exigirá. De acordo com Velho, "os conceitos e orientações centrais do trabalho de Campbell (como teodicéia, individualismo etc.) - sem falar do seu paradigma, em que se inclui o próprio dualismo Ocidente-Oriente com que norteia o trabalhosão, rigorosamente, ocidentais. Ou, quiçá mesmo, orientalistas. Até que ponto isso não compromete a noção de um paradigm shift?" (p.26).

Outra questão assinalada por Velho (1997) refere-se à importância de ter em mente que, ao se pensar em uma mudança de paradigma, como a sugerida por Campbell, não se pode "reduzir as diferenças internas que sempre caracterizaram e emprestaram dinamismo a nossa sociedade" (p.26), como, por exemplo, o ressurgimento da gnose, sobretudo entre as tradições religiosas americanas, e a existência de todas as misturas e os sincretismos que compõem a cultura religiosa brasileira.

Nessa mesma linha, por fim, Velho (1997) explora a temática da ética do século XXI, cerne dos debates da conferência internacional A Ética do Século XXI, realizada em julho de 1997, no Rio de Janeiro, em que foram apresentados os dois textos aqui discutidos. $\mathrm{O}$ autor comenta, então, que o texto de Campbell sobre a orientalização do Ocidente dá continuidade ao livro A ética romântica e o espírito do consumismo moderno (Campbell, 2001) e traz à tona "o 'outro' protestantismo que não o de Calvino, examinado por Weber, e que viria a se expressar através do Romantismo" (Velho, 1997, p.27). Afirma ainda que um dos traços principais de todo esse movimento estaria na "negação do pessimismo fundamental do calvinismo (se não do próprio Weber) - sobretudo a propósito da natureza humana - e que ganharia grande impulso com o Iluminismo" (p.27). Velho acredita que esse otimismo precisaria ser relativizado, sobretudo em relação à natureza humana, questionando a hipótese de que o paradigm shift possa repousar exclusivamente sobre o veio romântico.

Estaria de fato o Ocidente se orientalizando? Responder a essa pergunta de forma definitiva talvez seja impossível e de qualquer modo escaparia aos objetivos desta reflexão. O importante, contudo, seria identificar os processos que permitiram não apenas a aceitação, mas a valorização e a busca ativa de produtos identificados como orientais, entre os quais formas específicas de práticas terapêuticas, configurando a superfície de emergência para certos discursos sobre a saúde que, do Ocidente, assumem uma perspectiva soi-disant oriental. 


\section{Novos paradigmas em saúde}

Com base na linha foucaultiana de indagação, procuraremos, na parte final desta reflexão, traçar as condições de possibilidadeconfiguradas pelo processo de orientalização do Ocidente - para o florescimento de novas práticas de saúde na sociedade ocidental.

De fato, não se pode compreender o crescimento vertiginoso da demanda pelas chamadas medicinas alternativas no Brasil e no mundo a partir da segunda metade da década de 1970, sem situar o quadro cultural da época. Luz (1997), ao discorrer sobre a cultura contemporânea e as medicinas alternativas, enfatiza a importância do 'grande boom contraculturalista' nos anos 70, que trouxe à tona uma diversidade de práticas terapêuticas consumidas pelos setores de vanguarda da classe média. Considerando-se o papel de formadores de opinião desses setores, observou-se uma grande tendência à difusão dessas práticas.

Todos esses sistemas terapêuticos e práticas de medicação e cuidado ligados aos movimentos de contracultura tinham originalmente em comum uma posição antitecnológica em relação à saúde, tendente ao naturismo:

Defendiam formas simplificadas e não invasivas no tratamento de doenças, o consumo de medicamentos oriundos de produtos naturais (não químicos) e uma proposta ativa de promoção da saúde (distinta do preventivismo médico), ao invés da postura tradicional de combate às doenças, característica da medicina científica. Nesse caso, o naturismo significa não apenas a rejeição da medicina especializada e tecnificada, por ser invasiva e iatrogênica, portanto antinatural, mas também a afirmação da força curativa da natureza e da eficácia maior das terapêuticas provenientes da natureza. (Luz, 1996a, p.274)

Note-se, porém, que a recepção desse movimento cultural no Brasil se deu num momento de intensa repressão política, em meio à fase mais dura da ditadura militar, o que levou à fragmentação das ideologias subjacentes em campos apartados pela política de então. Enquanto os ideais políticos eram incorporados pelos movimentos de contestação ao regime - que desembocariam nas tentativas de luta armada -, os aspectos com implicações diretas para as práticas terapêuticas terminaram associados ao que se denominava então, de forma pejorativa, 'desbunde'.

Mais adiante, Luz (1996a) afirma que as medicinas naturais cujo estoque terapêutico é em grande parte baseado em produtos fitoterápicos obtiveram o seu renascimento no mundo ocidental graças ao sucesso cultural das civilizações do Oriente, sobretudo da Îndia e da China, que caracterizaram a década de 1960: 
A busca social de culturas médicas orientais, intensificada a partir dos anos 70, sobretudo das medicinas chinesa e hindu, com suas visões da saúde do homem ditas holistas ou integrais, mas de fato profundamente espiritualizadas, é sintoma de um abalo sísmico de natureza ideológica que tem se mantido e propagado desde então na cultura ocidental, com maior ou menor intensidade nacional ou conjuntural ... Esse abalo atinge a cosmovisão que informa a medicina científica moderna, sua concepção tecnicista e atomizante do homem e de suas doenças, concepção baseada na física clássica herdada de Newton e na visão dualista (corpo/alma) do ser humano herdada de Descartes. (Luz, 1996a, p.274-275)

Com a chegada do movimento de contracultura à América Latina, os novos modelos em cura e saúde, demandados inicialmente por faixas populacionais jovens de classe média das grandes cidades, foram se solidificando, nestes últimos vinte anos, na cultura urbana como um todo. Geralmente trata-se de terapias derivadas de sistemas médicos complexos tradicionais do Oriente, que têm sua própria racionalidade, como a medicina tradicional chinesa e a medicina ayurvédica, ou ainda a homeopatia e a fitoterapia popular. Todas essas terapias foram vistas como formas mais 'naturais' de tratar as doenças, menos invasivas e menos iatrogênicas que a medicina convencional.

Assim, em tempos de orientalização, com o crescimento das medicinas tradicionais orientais em nosso meio um novo paradigma médico pode estar surgindo, trazendo inovações relativas aos seguintes aspectos: reposição do sujeito doente como centro do paradigma médico; re-situação da relação médico-paciente como elemento fundamental da terapêutica; busca de meios terapêuticos simples, menos caros, com igual ou maior eficácia em termos curativos nas situações mais gerais e comuns de adoecimento da população; construção de uma medicina que busque acentuar a autonomia do paciente; afirmação de uma medicina que tenha a saúde e não a doença como categoria central de seu paradigma (Luz, 1997).

Entretanto Martins (1999), em seu artigo “Novos paradigmas e saúde" , a partir de uma análise filosófico-epistemológica, argumenta que a medicina ocidental 'científica' não se constitui somente sob o paradigma mecanicista, que aliás já não predomina nas ciências contemporâneas, e aponta o surgimento, no 'interior' da ciência ocidental, do 'paradigma quântico', que redefiniria os próprios conceitos de ciência e razão. Em suas palavras:

Para nos inserirmos em um paradigma no qual natureza e cultura, homem e mundo, mente e corpo existem como aspectos de uma mesma Natureza (ou substância) não separável, não é preciso sair da ciência. Basta acompanhá-la, em sua contemporaneidade quântica. Isto é, transformá-la e acompanhar o paradigma que emerge dessa transformação. (Martins, 1999, p.106) 
5 A esse respeito ver, entre outros, Camargo Jr. (1997; 1998; 2002).
Dessa forma, segundo Martins (1999), no lugar de uma medicina científica ocidental podemos pensar, não obrigatoriamente em uma medicina oriental que a substitua, mas em uma medicina diferentemente científica, afinada com os novos paradigmas contemporâneos, tanto científicos como sociais ou culturais.

Embora concordemos com a idéia de que o imaginário científico da medicina é coerente com o modelo da física clássica, newtoniana (Camargo Jr., 1997), a posição de Martins nos parece excessivamente voluntarista. Com efeito, Sayd (1999), ao estabelecer um diálogo com a proposição de Martins, lembra que a medicina ocidental biomecânica ou biomedicina, reducionista, mecanicista e baseada em paradigmas científicos ultrapassados - mesmo que não haja nenhum imperativo filosófico ou epistemológico para que seja assim -, "existe desta forma e não de outra" (p.114), pois responde a uma aspiração coletiva. Ao se dizer científica, transmite "uma apaziguadora aparência de certeza e inquestionabilidade" (p.114), o que todos querem ao falar do imprevisível da natureza e da morte. Abandonar essa ideologia médica, partilhada socialmente, é muito mais do que abrir mão um preconceito irracional, uma visão estreita e ultrapassada de ciência; é abandonar toda uma visão de mundo, uma cultura e até mesmo uma ética. ${ }^{5}$

Assim, podemos identificar, de acordo com Sayd (1999), tanto a linha de pesquisa Racionalidades Médicas, desenvolvida por Mabel Luz no Instituto de Medicina Social da Universidade do Estado do Rio de Janeiro, quanto a proposta de novos paradigmas em saúde presente no texto de Martins (1999), como indicadores da busca pela mudança de paradigma cultural que Campbell descreve, ao modo de tipo ideal, como o processo de orientalização do Ocidente.

Ainda que discordando de algumas conclusões de Martins (1999), é possível encontrar, em seu texto, corroboração à afirmação de Campbell (1997, p.13) de que "um processo de orientalização não tem que depender simplesmente de uma importação de idéias exógenas, mas pode ser entendido como facilitado pela presença de uma tradição cultural nativa ao Ocidente".

Paralelamente aos novos paradigmas em saúde, surgem os movimentos ecológicos e ambientais, que vêm ganhando força no cenário mundial, tematizando a questão da vida como um todo e da unidade do homem com a natureza, numa perspectiva que, como vimos, é (re)construída como oriental. Observa-se, então, a insatisfação com vários aspectos da vida contemporânea, materializada nos discursos da contracultura das décadas de 1960 e 1970, juntamente com um 'Oriente' reinventado a partir da assimilação parcial e seletiva de práticas e discursos tradicionais de países asiáticos. Estariam assim dadas as condições de possibilidade tanto de uma visão crítica de aspectos específicos da sociedade industrial ocidental 
- em particular das formas de cura sancionadas oficial e legalmente pela biomedicina -, quanto da proposição de alternativas.

\section{Considerações finais}

Campbell (1997) trata a dicotomia Oriente/Ocidente ao modo de tipo ideal de Weber. Apesar de o esquema que idealiza apresentar uma certa rigidez, mostra-se útil para identificarmos as principais diferenças entre os pensamentos oriental e ocidental. Ancorado no trabalho de psicólogos sociais, o autor identifica como orientais aquelas pressuposições básicas comuns ao budismo, taoísmo, confucionismo e hinduísmo, e como ocidentais aquelas presentes nas religiões judaico-cristãs e, até certo ponto, subjacentes ao pensamento grego.

Com base numa ampla variedade de fontes, identifica o monismo como a característica mais importante do pensamento oriental, em contraste com o dualismo do pensamento ocidental. Ou seja, para o Oriente, homem e natureza, espiritual e físico, mente e corpo são um. O homem deveria, então, reconhecer sua unidade com toda a existência e sentir-se à vontade em qualquer lugar e com qualquer pessoa. Para o Ocidente, o homem tem características que o separam da natureza e do espiritual; o homem é dividido em corpo, mente e espírito; há um deus pessoal que está acima do homem; o homem deve controlar e manipular a natureza para garantir sua sobrevivência. Enquanto que, para o Oriente, ciência e tecnologia criam, na melhor das hipóteses, uma ilusão de progresso, para o Ocidente elas representam a principal esperança num futuro melhor (Campbell, 1997, p.8).

Como desdobramento do movimento de contracultura no Brasil e no mundo, uma perspectiva oriental se desenhou nos horizontes do Ocidente. Despontam então, como um leque de possibilidades, uma nova consciência ética, uma nova mentalidade, uma nova forma de vida, baseadas todas nos princípios de imanência, nos quais não se verificam as já citadas oposições homem/natureza, espiritual/físico, corpo/mente. No entanto para o imaginário ocidental, carente de sincronia com o referencial de mundo que inicialmente deu origem a essa perspectiva, tornou-se necessário reinventar um universo oriental. A partir dessa recriação, difundida através do complexo prisma da mídia moderna no mundo globalizado, surgiram novas práticas terapêuticas derivadas de antigos e tradicionais sistemas de cura. Desse modo, o contraste entre as cosmologias oriental e ocidental perpetua-se também no campo da saúde, marcando as diferenças entre a medicina ocidental contemporânea, ou biomedicina, e as práticas holísticas.

Sabemos que a biomedicina surgiu entre os séculos XVI e XVII em conseqüência de mudanças cruciais na visão de mundo daque- 
la época, dando lugar a explicações mecanicistas dos fenômenos do adoecimento, à fragmentação do conhecimento em especialidades e a uma visão dualista do homem. Porém a emergência de sistemas de cura tradicionais, baseados em filosofias não-dualistas de integração entre homem e cosmo, em paralelo com a biomedicina, pode ser vista como resultado de mais uma mudança sociocultural - a alternância histórica de uma teodicéia ocidental para uma outra que se aproxima cada vez mais da oriental.

Por fim, retomando Foucault e nossa pergunta original, parecenos possível afirmar que esses profundos movimentos tectônicos na cultura, ao repercutir especificamente sobre determinados grupos sociais e, no nosso caso, em particular num conjunto de médicos que se formava e/ou iniciava sua prática profissional ao longo das décadas de 1970 e 1980, ao mesmo tempo refletem e organizam toda uma série de insatisfações com as limitações percebidas na aplicação estrita do modelo biomédico. Concomitantemente oferecem quadros referenciais alternativos que relêem e reinventam, na mais pura tradição antropofágica brasileira, não uma, mas várias 'medicinas chinesas'. Em suma, o que permitiu a esses médicos tornarem-se 'chineses' foi a formação, a partir da contracultura, de uma superfície de emergência foucaultiana que faz com que, num certo sentido, a 'China' seja aqui.

\section{REFERÊNCIAS E BIBLIOGRAFIA}

Appadurai, Arjun 1996

Camargo Jr., Kenneth R. 2002

Camargo Jr., Kenneth R. 1998

Camargo Jr., Kenneth R. 1997

Camargo Jr., Kenneth R. 1992

Campbell, Colin 2001

Campbell, Colin 1997

Clarke, John J. 1997

Foucault, Michel 1999

Foucault, Michel 1990
Disjuncture and difference in the global cultural economy. In: Appadurai, Arjun. Modernity at large: cultural dimensions of globalization. Minneapolis: University of Minnesota Press.

The thought style of physicians: strategies for keeping up with medical knowledge. Social Studies of Science, London, v.32, n.6, p.827-855.

Medicina, médicos, doenças e terapêutica: exame crítico de alguns conceitos. Rio de Janeiro: IMS/Uerj. (Série Estudos em Saúde Coletiva, 170).

A biomedicina.

PHYSIS - Revista de Saúde Coletiva, Rio de Janeiro: IMS/Uerj, v.7, n.1, p.45-68.

Paradigmas, ciência e saber médicos. Rio de Janeiro: IMS/Uerj. (Série Estudos em Saúde Coletiva, 6).

A ética romântica e o espírito do consumismo moderno. Rio de Janeiro: Rocco.

A orientalização do Ocidente: reflexões sobre uma nova teodicéia para um novo milênio. Religião e Sociedade, Rio de Janeiro, v.18, n.1, p.5-22.

Oriental enlightenment: the encounter between Asian and Western thought. London: Routledge.

História da loucura na idade clássica. 6.ed. São Paulo: Perspectiva. (Coleção Estudos).

As palavras e as coisas: uma arqueologia das ciências humanas. 5.ed. São Paulo: Martins Fontes. 


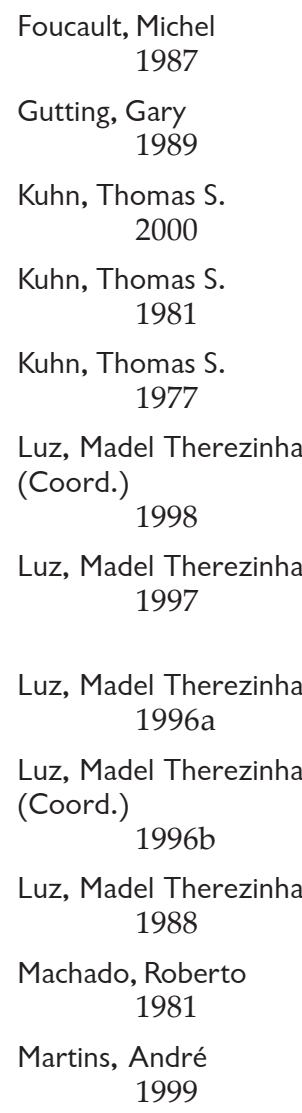

Nascimento, Marilene Cabral 1997

Nogueira, Maria Inês 2003

Said, Edward W. 1990

Sayd, Jane D. 1999

Spink, Mary Jane P. (Org.) 2000

Velho, Otávio 1997
A arqueologia do saber.

3.ed. Rio de Janeiro: Forense-Universitária.

Michel Foucault's archeology of reason.

Cambridge (UK): Cambridge University Press.

The road since structure: philosophical essays, 1970-1993.

Chicago: The University of Chicago Press.

A estrutura das revoluções científicas.

3.ed. São Paulo: Perspectiva.

A tensão essencial.

Lisboa: Edições 70 (Biblioteca de Filosofia Contemporânea).

VII Seminário do projeto racionalidades médicas. Rio de Janeiro: IMS/Uerj.

(Série Estudos em Saúde Coletiva, 160, 167 e 168).

Cultura contemporânea e medicinas alternativas: novos paradigmas em saúde no fim do século XX. Physis - Revista de Saúde Coletiva, Rio de Janeiro: IMS/Uerj, v.7, n.1, p.13-43.

$A$ arte de curar versus a ciência das doenças: história social da homeopatia no Brasil. São Paulo: Dynamis.

$V$ e VI Seminários do projeto racionalidades médicas. Rio de Janeiro: IMS/Uerj. (Série Estudos em Saúde Coletiva, 136 e 140).

Natural, racional e social: razão médica e racionalidade científica moderna. Rio de Janeiro: Campus.

Ciência e saber: a trajetória da arqueologia de Foucault.

2.ed. Rio de Janeiro: Graal.

Novos paradigmas e saúde.

Physis - Revista de Saúde Coletiva, Rio de Janeiro, v.9, n.1, p.83-112.

Da panacéia mística à especialidade médica: a construção do campo da acupuntura no Brasil. Dissertação (Mestrado) - Instituto de Medicina Social, Universidade do Estado do Rio de Janeiro, Rio de Janeiro.

Entre a conversão e o ecletismo: de como médicos brasileiros tornam-se 'chineses'. Tese (Doutorado em Saúde Coletiva) - Instituto de Medicina Social, Universidade do Estado do Rio de Janeiro, Rio de Janeiro.

Orientalismo: o Oriente como invenção do Ocidente.

São Paulo: Companhia das Letras.

Novos paradigmas e saúde: notas de leitura.

Physis - Revista de Saúde Coletiva, Rio de Janeiro: IMS/Uerj, v.9, n.1, p.113-121.

Práticas discursivas e produção de sentidos no cotidiano: aproximações teóricas e metodológicas. 2.ed. São Paulo: Cortez.

A orientalização do Ocidente: comentários a um texto de Colin Campbell. Religião e Sociedade, Rio de Janeiro, v.18, n.1, p.23-29. 